\title{
La reforma del Poder Judicial debe tener una dimensión política de la que no se habla
}

\author{
MARCIAL ANTONIO RUBIO CORREA
}

\begin{abstract}
SUMARIO: I. INTRODUCCIÓN.- II. LA ADMINISTRACIÓN DE JUSTICIA Y, DENTRO DE ELLA, EL PODER JUDICIAL, ESTÁN MAL PENSADOS EN EL PERÚ.- III. EL PODER JUDICIAL NO ES UN PODER POLÍTICO DENTRO DEL ESTADO Y DEBE SERLO.- IV. UNA RAÍZ HISTÓRICA DE LA NATURALEZA POLÍTICA DE LA ADMINISTRACIÓN DE JUSTICIA.- V. EL MODELO DE UN JUEZ QUE "APLICA» LA LEY LLEGA HASTA NOSOTROS Y TAMBIÉN TIENE ORIGEN POLÍTICO.- VI. LA INTERVENCIÓN DE MONTESQUIEU EN EL DISEÑO DEL MODERNO PODER JUDICIAL.- VII. CÓMO PODER DISEÑAR LAS FUNCIONES DE UN PODER JUDICIAL CON SUS DIMENSIONES POLÍTICA Y TÉCNICO-JURÍDICA.- VIII. EL ESQUEMA INSTITUCIONAL PARA EL GOBIERNO DEL PODER JUDICIAL.- IX. A MANERA DE REFLEXIÓN FINAL.
\end{abstract}

\section{INTRODUCCIÓN}

Este es un escrito que no juzga ni critica la conducta de persona alguna. Pretende explicar lo que nos parece un problema estructural en el Poder Judicial y en su reforma para desarrollo y progreso de la administración de justicia. Guardamos el mayor respeto por la labor de los magistrados judiciales pero, para decirlo de manera gráfica, consideramos que va en un vagón del tren del Estado que no está concebido para avanzar a la velocidad de desarrollo de los otros. También pensamos que no se trata de reformarlo o remozarlo sino de repensarlo en el contexto de la organización constitucional del Estado.

Utilizaremos aquí el concepto de lo político como el interés y trabajo por la cosa pública, no como lucha de los partidos políticos por hacerse del poder y gobernar. Consideramos que la administración de justicia tiene una dimensión técnico-jurídica que le es consustancial, pero cuyo objetivo definitivo no es resolver todos los procesos judiciales posibles sino pacificar la sociedad y eliminar eficientemente sus conflictos con las armas del Derecho. Creemos que los jueces peruanos, de buena fe, consideran que su tarea es lo primero y que, a la larga, por una serie de costumbres que se transforman en cultura institucional, pueden sacrificar la pacificación al activismo de la resolución de procesos. Creemos que, si una reflexión reposada sobre estos temas nos lleva a esta conclusión, debemos tratar de cambiar esa cultura institucional y las bases organizativas sobre las que reposa. 
La agenda técnica de la reforma del Poder Judicial ha sido desarrollada extensamente en los trabajos internacionales sobre el tema y, también, está claramente especificada en el ámbito interno peruano. Puede ser revisada en el Plan Nacional de Reforma Integral de la Administración de Justicia de la Comisión Especial para la Reforma Integral de la Administración de Justicia - CERIAJUS, diseñado en Lima el 23 de abril de 2004. ${ }^{1}$ También hay aportes al tema en la obra Gobierno y administración del Poder Judicial, organización de la función jurisdiccional y sistema de carrera judicial de la que es editor Francisco Eguiguren; ${ }^{2}$ en el trabajo de Javier de Belaunde, titulado La reforma del sistema de justicia. iEn el camino correcto?; ${ }^{3}$ y en el libro editado por Henry Pease García y Giofianni Peirano Torriani, a propósito del Seminario durante los noventa años de la Pontificia Universidad Católica del Perú, sobre reforma del Estado peruano. ${ }^{4}$

No obstante ello, y a pesar de que el informe de la CERIAJUS tiene un alto grado de aceptación como núcleo de ideas, no ha sido debidamente ejecutado en los cuatro años y medio que han transcurrido desde su finalización y presentación pública. La pregunta es: si la reforma judicial es tan importante y hay ideas claras, ipor qué no se lleva a cabo?

Existe un conjunto de elementos a tener en cuenta para dar respuesta a esta pregunta. Usualmente se esgrimen falta de decisión política, falta de presupuesto y falta de voluntad de ejecución. Nosotros, sin embargo, creemos que tras esta incapacidad de realizar la reforma hay, también, un problema de estructura política del Poder Judicial, y de ello trata este artículo. Si este problema se aborda y resuelve, tal vez la reforma del Poder Judicial vaya hacia delante; tal vez, no. Pero, si no se aborda, no habrá tal reforma, como no la ha habido en todos estos años.

\section{II.LA ADMINISTRACIÓN DE JUSTICIA Y, DENTRO DE ELLA, EL PODER JUDICIAL, ESTÁN MAL PENSADOS EN EL PERÚ}

La Constitución peruana es, para nosotros, un texto normativo de muchas buenas intenciones pero con tremendos defectos formales, ${ }^{5}$ de

1 La versión íntegra del informe puede consultarse en la siguiente página <www.congreso.gob.pe/ comisiones/2004/ceriajus>.

2 Eguiguren Praeli, Francisco José (coordinador). Gobierno y administración del Poder Judicial, organización de la función jurisdiccional y sistema de carrera judicial. Lima: Fondo Editorial PUCP, 2002.

3 Belaunde López de Romaña, Javier de. La reforma del sistema de justicia ¿En el camino correcto? Lima: Instituto Peruano de Economía Social de Mercado y Konrad Adenauer Stiftung, 2006.

4 Capítulo V: «Exposición del Presidente de la Corte Suprema de Justicia de la República y Presidente del Poder Judicial, doctor Francisco Távara C.». En Henry Pease García y Giofianni Peirano Torriani (editores). Reforma del Estado peruano. Lima: Fondo Editorial PUCP, 2008.

5 La nuestra es la única Constitución Política de Estado que conocemos en el mundo que tiene una errata oficial que cumplió un cuarto de siglo el 31 de diciembre de 2008: precisamente, al tratar de los principios y derechos de la función jurisdiccional que aquí nos ocupan, puede verse que el inciso 15 del artículo 139 está íntegramente repetido dentro del inciso 14. Sin duda, una desatención del mecanógrafo que se convierte en fuente oficial de Derecho sin que el Congreso haya hecho profilaxia legislativa elemental y de decencia a lo largo de veinticinco años. 
técnica y de concepto. Esto es perfectamente aplicable al tema de administración de justicia y del Poder Judicial. Repasémoslos brevemente.

El artículo 139, inciso 1, de la Constitución dice: «Son principios y derechos de la función jurisdiccional: 1. La unidad y exclusividad de la función jurisdiccional. No existe ni puede establecerse jurisdicción alguna independiente, con excepción de la militar y la arbitral [...]».

No entraremos aquí en la discusión de si la militar y la arbitral son jurisdicciones. El hecho es que no hay unidad y exclusividad de función jurisdiccional, mas si hay entidades independientes que ejercen jurisdicción. Además, el inciso 1 del artículo 139 de la Constitución está equivocado, porque otros dispositivos constitucionales también otorgan atribuciones jurisdiccionales independientes al Jurado Nacional de Elecciones (artículos 142 y 181), al Tribunal Constitucional (artículo 202) y a las autoridades comunales dentro de sus ámbitos territoriales (artículo 149). A nuestro criterio, el artículo 142 de la Constitución también da carácter jurisdiccional a la evaluación y ratificación de jueces en manos del Consejo Nacional de la Magistratura, pero, que sepamos, esto no se ha sostenido por otros y tampoco ha aparecido en las enumeraciones del Tribunal Constitucional cuando trata de los órganos con jurisdicción.

De manera que hay desorden y desestructuración dentro de la Constitución cuando se tratan los temas de administración de justicia y de los órganos encargados de ella. Es mala señal respecto a la importancia que el constituyente da a estos aspectos del Estado y de la pacificación social.

Vinculado con este primer defecto, hay uno segundo: sistemáticamente, el capítulo VIII del título IV de la Constitución se denomina «Poder Judicial», pero su contenido más trascendente lo constituyen los principios y derechos de la función jurisdiccional, normados en el artículo 139, que deben ser obedecidos por todos aquellos que ejercen jurisdicción y no solo por el Poder Judicial, como podría hacer suponer una equivocada interpretación por la ubicación de la norma dentro del sistema jurídico. ${ }^{6}$

La organización del Poder Judicial no es clara en absoluto, como sí lo son la del Legislativo o la del Ejecutivo:

- El artículo 143 dice, simplemente, que «El Poder Judicial está integrado por órganos jurisdiccionales que administran justicia en nombre de la Nación, y por órganos que ejercen su gobierno y administración». Los

6 El tema es relevante porque el Tribunal Constitucional tuvo que hacer explícitamente esta precisión. Dijo: «32. Conforme a lo expuesto, ningún órgano estatal está autorizado para funcionar desvinculado de la Norma Suprema, toda vez que las denominadas "garantías judiciales", consagradas tanto en nuestra Norma Fundamental como en la Convención Americana de Derechos Humanos, no sólo son de aplicación en sede del Poder Judicial, sino también en cualquier otro ámbito en el que se ejerza, formal o materialmente, funciones de naturaleza jurisdiccional, como es el caso de los órganos que integran la jurisdicción militar». Sentencia del Tribunal Constitucional emitida el 09 de junio de 2004 en el expediente 0023_2003_Al_TC, sobre acción de inconstitucionalidad interpuesta por la Defensoría del Pueblo; en diversos artículos del decreto ley 23201, Ley Orgánica de Justicia Militar; del decreto ley 23214, Código de Justicia Militar; y de la ley 27860, del Ministerio de Defensa. 
órganos jurisdiccionales están mencionados, cuando menos con referencias esenciales, pero los de gobierno y administración no lo están en absoluto.

- La distinción entre lo que pertenece al ámbito jurisdiccional y los de gobierno y administración no es clara ni en la Constitución ni en la Ley Orgánica del Poder Judicial. A nuestro criterio, las atribuciones de la Sala Plena de la Corte Suprema, establecidas en el artículo 80 de la Ley Orgánica del Poder Judicial, y las del Consejo de Gobierno del Poder Judicial, establecidas en el artículo 81 del mismo cuerpo legal, no tienen una clasificación adecuada y, por tanto, no distinguen en forma debida lo jurisdiccional de lo demás. En el libro editado por Francisco Eguiguren con el título Gobierno y administración del Poder Judicial, organización de la función jurisdiccional y sistema de carrera judicial ya citado antes, todo el capítulo I de la primera parte está destinado a estudiar este tema. Nosotros trabajaremos sobre ello en páginas posteriores.

- La Corte Suprema es descrita en la Constitución como un órgano de funciones estrictamente jurisdiccionales y no como un órgano de conducción de la administración de justicia. El artículo 141 de la Carta dice: «Corresponde a la Corte Suprema fallar en casación, o en última instancia, cuando la acción se inicia en una Corte Superior o ante la propia Corte Suprema conforme a ley. Asimismo, conoce en casación las resoluciones del Fuero Militar, con las limitaciones que establece el artículo 173».

- Los magistrados de la Corte Suprema son seleccionados y elegidos por sus cualidades jurisdiccionales, no por su capacidad de gobernar una estructura institucional de miles de jueces y de más de diez mil empleados, con presencia en todo el territorio nacional.

Todas estas normas demuestran que, en el plano constitucional, el Poder Judicial y su conducción, así como la administración de justicia en general, están tratados desprolijamente, sin un orden consistente y una clasificación de funciones que tenga racionalidad dentro del concepto moderno de la gestión de instituciones públicas. Este desorden, que es del constituyente y no del juez, es una clara demostración de que, en materia diseño institucional, el Perú no tiene una idea clara de cómo legislar la administración de justicia y el Poder Judicial.

\section{EL PODER JUDICIAL NO ES UN PODER POLÍTICO DENTRO DEL ESTADO Y DEBE SERLO}

En el Perú, el Poder Judicial no es, desde el punto de vista institucional, un poder político, y las razones son a nuestro juicio dos:

La primera, que no tiene legitimación electiva y, por consiguiente, el poder que ejerce carece de fundamento democrático. Debemos destacar 
que, a nuestro criterio, el juez que realiza función jurisdiccional debe tener competencia profesional y no legitimación democrática, pero quien ejerce el gobierno del Poder Judicial sí debe tenerla, sea una persona o un organismo colegiado. Esto, desde luego, exige que previamente al diseño institucional del Poder Judicial se diferencien los aspectos que pertenecen a la política y administración, de un lado, y los que pertenecen a la labor propiamente jurisdiccional, del otro, a fin de separarlos como atribuciones específicas de cada grupo de magistrados: los políticos y los jurisdiccionales.

La segunda, que el Poder Judicial parece tener actualmente por misión esencial dar trámite a los procesos de manera técnica y no la que creemos es su misión esencial: pacificar el país. Esto, en nuestro criterio, se muestra de diversas maneras. Algunas, al azar, son las siguientes:

a. La Corte Suprema no ha considerado como su función impulsar la jurisprudencia vinculante en el país. Solo en los últimos tiempos, y sin negar la importancia de estos recientes aportes, ha iniciado esta tarea de manera fragmentaria.

b. Tampoco la Corte Suprema ha promovido convertirse de instancia de resolución de procesos en órgano de orientación de la actividad jurisdiccional con una carga procesal menos agobiante, que le permita dictar sentencias de fondo como precedentes vinculantes y en los temas trascendentales. ${ }^{7}$

c. Muchas veces, un tribunal no tiene rubor alguno en devolver el trámite de un largo proceso a sus primeros pasos al dictar la existencia de una nulidad, sin evaluar ni fundamentar si regresar a las primeras fojas el expediente es mejor para la pacificación que aplicar la regla invalidante. El culto a la forma es una prueba sumamente indicativa de la preferencia de la misión técnica por sobre la misión política de pacificar.

d. Los jueces tienen una inmensa sabiduría sobre los procesos y sus principales problemas de celeridad. Sin embargo, nunca se ve que el Poder Judicial como conjunto sea una fuerza poderosa de modificación y simplificación de los procedimientos existentes. Antes bien, su actitud inmensamente preponderante es aplicarlos tal como son.

Podríamos añadir muchos otros elementos de hecho, pero solo estos ya demuestran claramente, a nuestro juicio, que no está en el debate usual de los jueces su tarea de pacificación social sino que, más bien, dan preferencia a su actuar de manera técnicamente adecuada, con un apego especial a las formas. En nuestra opinión, este es un tema de cultura institucional y no uno de incapacidad: los jueces asumen que las cosas

7 El Tribunal Constitucional ha dictado sentencias en las que ha regulado las materias de las cuales se ocupará y aquellas otras de las que no $-\mathrm{y}$ que considera deben ser transferidas al proceso contenciosoadministrativo-. No hay empeño semejante en la Corte Suprema, la que, aunque tiene una regulación distinta a la del Tribunal Constitucional, no ha mostrado un real interés en asumir esta actitud.

LA REFORMA DEL PODER JUDICIAL DEBETENER UNA DIMENSIÓN POLITTICA DE LA QUE NO SE HABLA 
se hacen así. Solo cuando las instituciones son sopladas por una enérgica conducción de transformación, se animan a repensar su quehacer y a transformarlo. Aún con conducción política enérgica, tal cometido suele ser solo parcialmente logrado. El tema es, pues, de falta de estructuras para la conducción política y no de incapacidad para llevar adelante el cambio. Por ello sostenemos que el Poder Judicial tiene una dimensión política esencial y ella debe ser abordada para lograr efectivamente su reforma y desarrollo.

Los clásicos del pensamiento liberal, que son los que diseñaron el Estado que tenemos hoy, siempre consideraron que la autoridad común que zanja conflictos entre los ciudadanos es esencial para la existencia de la sociedad. John Locke es uno de ellos: consideraba que en el Estado de Naturaleza todos teníamos el poder de defendernos de las agresiones de los demás pero, al mismo tiempo, que la humanidad pasó a vivir en sociedad porque eso era un progreso. El requisito para vivir en sociedad fue que todos renunciáramos a nuestra fuerza para defendernos por nosotros mismos y la transfiriéramos a una autoridad que, con la ley preestablecida, zanjara los conflictos. Mucho de eso tenía que ver con la administración de justicia:

87. - Al nacer el hombre — como ya hemos probado— con derecho a la libertad perfecta y a disfrutar sin cortapisas todos los derechos y privilegios que le otorga la ley de naturaleza, y en igual medida que cualquier otro hombre o grupo de hombres en el mundo, no sólo tiene por naturaleza el poder de proteger su propiedad es decir, su vida, su libertad y sus bienes, frente a los daños y amenazas de otros hombres, sino también el de juzgar y castigar los infringimientos [sic] de la ley que sean cometidos por otros, y en el grado que la ofensa merezca; tendrá incluso el poder de castigar con la pena de muerte cuando, en su opinión, la atrocidad del crimen así lo requiera. Ahora bien, como no hay ni puede subsistir sociedad política alguna sin tener en sí misma el poder de proteger la propiedad y, a fin de lograrlo, el de castigar las ofensas de los miembros de dicha sociedad, única y exclusivamente podrá haber sociedad política allí donde cada uno de sus miembros haya renunciado a su poder natural y lo haya entregado en manos de la comunidad, en todos aquellos casos en que no esté imposibilitado para pedir protección de la ley que haya sido establecida por la comunidad misma. Y así al haber sido excluido todo juicio privado de cada hombre en particular, la comunidad viene a ser un árbitro que decide según normas y reglas establecidas, imparciales y aplicables a todos por igual, y administradas por hombres a quienes la comunidad ha dado autoridad para ejecutarlas. Y de este modo, la comunidad decide las diferencias que puedan surgir entre sus miembros en cuestiones de derecho, y castiga aquellas ofensas que algún miembro haya cometido contra la asociedad [sic], con las penas que la ley haya estipulado. Guiándonos por todo esto, nos resultará fácil averiguar quiénes componen, y quiénes no, una sociedad política. Aquellos que están unidos en un cuerpo y tienen una establecida ley 
común y una judicatura a la que apelar, con autoridad para decidir entre las controversias y castigar a los ofensores, forman entre sí una sociedad civil; pero aquellos que carecen de una autoridad común a la que apelar - me refiero a una autoridad en este mundo- continúan en el estado de naturaleza; $y$, a falta de otra persona, cada uno es en sí mismo juez y ejecutor, lo cual es lo mismo que decir, como ya he mostrado antes, que se halla en el más absoluto estado natural. ${ }^{8}$

La administración de justicia está, en este texto, en el corazón de la política, y es razonable que así sea: no se podrá construir una sociedad fraterna y de progreso si priman los conflictos irresolubles y la justicia por propia mano sobre la racionalidad de la ley y la autoridad pública que cumple la función política -interés por la cosa pública - de pacificar y aunar esfuerzos en vez de fragmentarlos. Este es el origen verdadero de la función política de la administración de justicia y del Poder Judicial en el Estado contemporáneo, y tal función no caducó, sino que está presente como un prerrequisito de la organización política. Por eso es que aun hoy consideramos al Poder Judicial como uno de los tres poderes políticos del Estado.

Para que el Poder Judicial fuera un auténtico poder político del Estado debería tener unos órganos de conducción política que no se mezclaran con los órganos de función jurisdiccional ni interfirieran en su tarea, pues estos últimos deben mantener su característica de ser entidades técnicas de resolución de conflictos. La historia de la administración de justicia en el Perú demuestra que esta pareja de órganos judiciales no ha ido de la mano.

La razón por la que ello ha ocurrido es, creemos, que al Poder Judicial siempre se le ha dicho lo que hoy le dice la Constitución a la Corte Suprema, según reseñamos antes: que su función es resolver procesos judiciales. Sin embargo, consideramos que alguien dentro del Poder Judicial, que no es quien resuelve los conflictos con técnica-jurídica, debe tener la función de pensar en la pacificación de la sociedad y en la relación entre dicha pacificación y la técnica.

El ser humano de hoy tiene una autoapreciación, dentro de la historia de la humanidad, de ser el más desarrollado, el más tecnificado, el que por fin conoce las cosas. ${ }^{9}$ Esto lo hace suponer, en el caso del Derecho, que nuestro sistema es mucho mejor que los que lo precedieron y que está mejor organizado. Sin embargo, la historia nos demuestra que no es así: que en el pasado hubo sistemas jurídicos extraordinariamente eficientes para el desarrollo de la humanidad — tal como ese desarrollo era entendido entonces, naturalmente- y que no fue cierto que la política y la técnica debieran estar divorciadas para que ello ocurriera. Todo lo contrario. 


\section{UNA RAÍZ HISTÓRICA DE LA NATURALEZA POLÍTICA DE LA ADMINISTRACIÓN DE JUSTICIA}

La idea de que la política —entendida como aquí hemos dicho que la concebimos - no tiene nada que ver con la administración de justicia es falsa, cuando menos, en la historia de los dos grandes sistemas occidentales de Derecho: el romano-germánico y el anglosajón.

En el Derecho romano de los primeros tiempos — desde los orígenes monárquicos hasta probablemente el siglo IV a.C., lo que incluye el período inicial de la vigencia de la Ley de las XII Tablas, fechada en el 450 ó 451 a.C.- el impulso principal de la aplicación del Derecho fue realizado por el Colegio de Pontífices Romano, una institución en la que se entremezclaban la labor jurisdiccional y religiosa. Era un órgano de constitución originalmente patricia y que, es fácil verlo, dirigía los aspectos jurídicos de la Roma de los primeros tiempos desde un lugar de preeminencia social, religiosa y política, que entonces eran tres dimensiones completamente entrelazadas de la vida pública. Dice al respecto el digesto:

Y así, casi en la misma época nacieron estos tres derechos a partir de la ley de las Doce Tablas: de ellas derivó el derecho civil y, de ellas procedió la formación de las acciones de la ley. Pero la ciencia de la interpretación de estas leyes así como el conocimiento de las acciones se hallaban en el colegio de los pontífices, de los que se designaba uno que cada año atendiera a los pleitos privados. Y el pueblo se atuvo a esta costumbre durante casi cien años. ${ }^{10}$

A su vez, Javier Paricio añade:

Aunque los pontífices formaran parte de la organización institucional romana desde tiempos muy remotos y tuvieran una autoridad enorme en el ámbito sacral, quizá su nota distintiva frente a otros sacerdotes fuera su capacidad y preparación intelectual, que los habilitaba como guardianes idóneos de los saberes y conocimientos más importantes para la comunidad, y por eso mismo no nos puede resultar extraño que durante la República muchos de los más importantes dirigentes de la aristocracia senatorial pertenecieran al colegio de pontífices, cuya condición, por lo demás, no resultó desde antiguo incompatible con otros cargos de gobierno. En este sentido cabe recordar que Cicerón, en el siglo I a.C., encontraba encomiable y debida a inspiración divina la tradición de los maiores [sic] que hacía descansar la dirección religiosa y política en las mismas manos. ${ }^{11}$

El año 367 a.C., fue establecido el pretor y, en 242 a.C., se separó a los pretores urbano y peregrino. Ellos fueron magistrados elegidos,

10 Digesto 1.2.6. Versión castellana por A. D’Ors, F. Hernández-Tejero, P. Fuenteseca, M. García-Garrido y J. Burillo. Pamplona: Editorial Aranzadi, 1968.

11 PARICIO, Javier. Los juristas y el poder político en la antigua Roma. Granada: Editorial Comares, 1999, pp. 26-27. 
con imperium y iurisdictio, que a lo largo de los siguientes dos a tres siglos renovaron y vigorizaron decisivamente el Derecho romano en todo tipo de relaciones: las de los romanos con los extranjeros, las de los extranjeros entre sí y las de los romanos entre sí.

El pretor no era un juez sino un político que prometía determinadas facilidades y características jurisdiccionales y que era elegido en función de tales promesas. Las propuestas de protección jurídica establecidas por el pretor fueron pronto recogidas en el Edicto del pretor, un documento que creció con los años. Se dice que las elecciones de los pretores se hicieron poco a poco de manera tal que el candidato prometía añadir determinadas vías de protección jurídica al edicto ya acumulado.

El pretor realizaba la primera etapa del proceso romano y luego el juzgamiento era realizado por el juez, quien juzgaba según las reglas establecidas por el pretor para el caso. Dice Kunkel:

[...] los romanos designaban con ius dicere y con el término de él derivado, iurisdictio, la actividad del magistrado jurisdiccional, el cual no daba él mismo la sentencia, sino que tenía únicamente la función de dirigir el proceso; más aún, sólo la de introducirlo. En la época republicana y en el procedimiento ordinario de la época del principado daban siempre la sentencia jueces privados. [...] La tajante división del curso del proceso en el estadio introductorio ante el magistrado (el proceso in iure) y la verdadera resolución ante el juez o jueces (alud indicem) se fue convirtiendo, de este modo, en una nota característica del proceso civil romano, la cual sólo había de desaparecer con el procedimiento extraordinario de la época imperial. ${ }^{12}$

La iurisdictio era la labor política del magistrado elegido; la iudicatio era la labor del juez nombrado:

La iurisdictio es la primera función propia de determinados magistrados romanos. Consiste, desde un punto de vista técnico, en determinar, ius dicere, la norma jurídica aplicable al caso concreto, dare actionem, o, en su caso, la ausencia de norma jurídica al respecto, lo que desembocaría en la negación de la actio, denegare actionem, y, en consecuencia, del cauce procesal para conocer de la supuesta pretensión. La iudicatio sería, en la primera etapa de bipartición del proceso, la función propia del juez unipersonal o del órgano colegiado, competente para valorar la prueba de los hechos alegados por las partes y decidir la solución del conflicto mediante la aplicación de la disposición legal predeterminada por el magistrado. ${ }^{13}$ 
En etapa posterior, son los juristas dotados de ius publice respondendi quienes impulsan nuevamente, durante otros dos o tres siglos, el desarrollo del Derecho romano hasta sus más altas expresiones. Pero estos juristas no eran simples especialistas: habían recibido del príncipe la atribución de dar respuestas jurídicas. El primero que otorgó esta autoridad a los juristas, según dicen los textos históricos del Derecho, fue el propio Augusto y la tradición fue seguida por los siguientes príncipes o emperadores. Sobre la vinculación con la autoridad política se puede encontrar esta referencia:

La frase fundamental que las fuentes ofrecen sobre el ius publice respondendi ex auctoritate principis corresponde al enchiridion de Pomponio, donde indica: «divus Augustus, ut maior iuris auctoritas haberetur, constituit, ut ex auctoritate eius responderent», es decir, que el divino Augusto, para que la autoridad del derecho (o de los juristas) fuera mayor, estableció que respondieran ex auctoritate eius, lo cual parece que debe interpretarse en el sentido de que el princeps, que tenía una auctoritas no parangonable a la de nadie, «reforzaba» $\mathrm{O}$ «aumentaba» la auctoritas de los juristas. ${ }^{14}$

Y luego el mismo autor añade lo siguiente:

Por lo que respecta a la eficacia de la respuesta (responsum) del jurista privilegiado en el caso concreto, ha sido, como casi todo en este ámbito, muy discutido. A mi modo de ver, resulta difícil sustraerse a la interpretación de que si las respuestas de los juristas privilegiados tenían una auctoritas mayor como consecuencia de venir reforzada por la acutoritas imperial, esas respuestas tenían que tener una consideración superior por parte de los jueces, y con toda seguridad debieron ser vinculantes oficialmente, al menos desde la época de Tiberio. ${ }^{15}$

De manera que también en los juristas del Derecho clásico romano hay una participación del poder público, no en lo que dicen, pero sí en su posibilidad de decirlo y de ser escuchados con especial atención.

Se trate del Colegio de Pontífices, del pretor o del jurista con ius publice respondendi, cualquiera de ellos ejerce el Derecho romano con intervención directa del poder público en la generación de la respuesta jurídica misma. Es evidente, por tanto, que en esta inmensa vertiente del Derecho occidental, y teniendo en cuenta sus peculiares instituciones políticas a lo largo del tiempo, la actividad jurisdiccional tiene una clara participación política, no obstante la cual se conforma un sistema jurídico de indiscutible trascendencia conceptual y técnica.

La historia es distinta en el Derecho anglosajón, pero no es menos directa la participación política: el derecho común inglés tiene su origen en la Corte del Rey que imparte justicia en nombre directo de él, muchas 
veces con su participación y, además, no solo por razones de justicia, sino también económicas, porque los ingresos que la monarquía inglesa tuvo en aquellos siglos por los mandatos reales a raíz de procesos judiciales fueron cuantiosos: «[...] en 1301 se registró que Eduardo I "obtuvo grandes tesoros" para pagar sus campañas militares "haciendo que la justicia cayera sobre los malhechores" ${ }^{16}$

Este mismo autor nos dice lo siguiente sobre la Corte Real inglesa del siglo XII:

Tal fue la actividad de esa corte real durante los setenta años siguientes que en 1180 se pudo escribir un tratado sobre Las leyes y costumbres de Inglaterra que se basó solamente en su funcionamiento. El tratado, tradicional pero dudosamente atribuido a Sir Ranulf de Glanvill (justiciero de Inglaterra 1180-1189), da la impresión de que la variedad de costumbres locales no había desaparecido para nada; de modo que el libro sólo presenta abiertamente un aspecto del Derecho de ese tiempo. El gran paso adelante del autor fue el tratamiento de las costumbres arraigadas de la corte real como constituyendo el jus et consuetudo regni, la ley y la costumbre del reino. [...] Glanvill y sus jueces colegas bajo el Rey Enrique II (1154-89) produjeron un sistema coherente de Derecho inglés derivando autoridad máxima del Rey. En contraste con este sistema uniforme, la costumbre local se vería a lo más como excepcional y a lo menos como recusable. ${ }^{17}$

Y para el siglo XVII inglés se dijo lo siguiente:

Los jueces de las cortes de common law eran, evidentemente, servidores del Rey. [...] el Rey era la fuente de toda justicia y ellos, solamente sus diputados: esta era la teoría fundamental del sistema, según la tradición, y era imposible romper con ella. [...] Con estas palabras, escritas en 1908, Frederick Matiland, probablemente el más grande historiador del Derecho inglés, describía la posición de la magistratura en la Inglaterra de principios del siglo XVII. La relación de los jueces con el Príncipe y, en general, con el poder político, no era muy diferente, desde un punto de vista constitucional, de la que regía en el continente, donde se había impuesto el absolutismo monárquico. ${ }^{18}$

16 BAKER, J.H. An Introduction to English Legal History. Londres: Butterworths, 1979, p 13. Traducción de María Elena Padilla Bendezú utilizada en los materiales de enseñanza del curso Historia de la Jurisdicción en la Maestría en Derecho con mención en Política Jurisdiccional de la Pontificia Universidad Católica del Perú, durante el primer semestre de 2000. La referencia a estos materiales es común para las demás citas de este libro en su versión en español. Para las dos citas incorporadas que nosotros hacemos, el autor cita Croniques de London. Camdem Society, 1844, pp. 28-29.

17 BAKER, J.H. Op. cit., p. 12.

18 Diez-PICAZo, Luis Maria. «Il modello europeo di magistratura: un approccio storico». En Magistrati e potere nella storia europea. Boloña: Societá Editrice II Mulino, 1997, p. 23. Traducción de María Fiorina Sanguinetti Chirif, utilizada en los materiales de enseñanza del curso Historia de la Jurisdicción en la Maestría en Derecho con mención en Política Jurisdiccional de la Pontificia Universidad Católica del Perú, durante el primer semestre de 2000. Esta referencia a la traducción es común para las siguientes citas de la misma obra colectiva. El autor cita a MaITLAND, F.W. The Constitutional History of England. Cambridge: 1979 [1908], p. 267. 
También el sistema anglosajón se construye sobre la base de la intervención del plano político, no en la decisión del juez pero sí en la administración de justicia. Las variantes históricas son diversas pero la regla es la misma: la concepción política de la solución de los conflictos es esencial para el desarrollo del Derecho, aunque la labor estrictamente jurisdiccional deba ser técnicamente desarrollada por los jueces. Es tan necesario lo uno como lo otro.

La política estuvo presente en el origen y desarrollo de estos dos sistemas altamente técnicos. Por supuesto, la política los acompañó en su desarrollo durante la Edad Media y a través de la época moderna que comienza a partir de fines del siglo XV y principios del siglo XVI. Solo que en estos tiempos la judicatura fue primero de clase noble y, luego, ocupada por jueces que compraron sus cargos a la corona. Fueron períodos de influencia política y de alta clase social en la judicatura, pero no son ejemplares para nuestro propósito en este texto.

\section{EL MODELO DE UN JUEZ QUE "APLICA» LA LEY LLEGA HASTA NOSOTROS Y TAMBIÉN TIENE ORIGEN POLÍTICO}

Un giro importante en la historia de la judicatura es el que ocurre en la Revolución francesa. Ella luchó contra los parlamentos jurisdiccionales franceses heredados del Antiguo Régimen, que pretendieron seguir aplicando las antiguas lois fondamentales como alternativa conservadora frente a las nuevas leyes que dictó la Asamblea Nacional en aquel momento. Esto llevó a los revolucionarios a exaltar el valor de la ley y a postergar las demás fuentes del Derecho, con lo que convirtieron al juez en lo que hoy denominaríamos un simple «funcionario de aplicación del Derecho positivo». Una interesante referencia a esto es la siguiente:

La transformación radical del modelo de magistratura se debió, entonces, a circunstancias y exigencias específicas de los revolucionarios franceses. Vale la pena mencionar dos de ellas. Por una parte, lo que ha sido bautizado como el «leggicentrismo» (leyes-centralismo) de la Revolución Francesa [sic], es decir la elevación de la ley, que es la expresión de la voluntad general, a una garantía suprema de libertad y de igualdad. ${ }^{19}$

Este rol central de la ley llevó a la formación de un sistema monista de fuentes normativas - todas las otras fuentes (costumbres, jurisprudencia de las cortes, etc.) existen como tales y tienen carácter obligatorio sólo en la medida en que sean reconocidas por el Derecho codificado y, sobre todo, ha creado la necesidad institucional de someter al juez a la supremacía de este sistema. Un tipo idealizado de juez demasiado culto,

19 En este punto, en la obra se cita de la siguiente manera: entre muchos otros, BAKER, K.M. «Costituzione». En F. Furet y M. Ozouf. Dizionario critico della rivoluzione Francese (Diccionario crítico de la Revolución francesa). Bompiani: 1994; García De EnTERRIA, E. La lengua de los derechos. La formación del Derecho Público europeo tras la Revolución francesa. Madrid: 1994. 
desenvuelto y consciente de su propia importancia, sería demasiado incompatible con la nueva fe legalista. ${ }^{20}$

Se puede así ver que el culto a la ley positiva que muestra mucha de la actividad jurisdiccional tiene su origen en una decisión política: el juez deja de ser un agente de interpretación y de aplicación de principios generales del Derecho y solamente aplica la ley. Fue muy fácil transferir este principio de la Francia revolucionaria al Perú independiente, en el cual las nuevas reglas debían convivir con las coloniales, pero en un sentido republicano e independiente. En el Perú, no se podía sustituir a todos los jueces de golpe, como no lo pudo hacer tampoco la Revolución francesa; pero sí se les podía imponer la aplicación de la ley positiva. Así ocurrió y aún no hemos roto completamente con ello.

\section{VI.LA INTERVENCIÓN DE MONTESQUIEU EN EL DISEÑO DEL MODERNO PODER JUDICIAL}

Del espíritu de las leyes, de Montesquieu, es un libro fundamental para las ideas de organización del Estado contemporáneo. El tema de la separación de poderes que se le atribuye como creación más importante se halla dentro del libro en el capítulo que trata de la Constitución inglesa. Allí, Montesquieu desarrolla sus ideas sobre la base de lo visto en la Inglaterra posterior a la Revolución Gloriosa de 1688 y, sobre lo estrictamente referente al Poder Judicial, dice lo siguiente:

Hay en cada Estado tres clases de poderes: el poder legislativo, el poder ejecutivo de los asuntos que dependen del derecho de gentes y el poder ejecutivo de los que dependen del derecho civil.

Por el poder legislativo, el príncipe, o el magistrado, promulga leyes para cierto tiempo o para siempre, y enmienda o deroga las existentes. Por el segundo poder, dispone de la guerra y de la paz, envía o recibe embajadores, establece la seguridad, previene las invasiones. Por el tercero, castiga los delitos o juzga las diferencias entre particulares. Llamaremos a éste poder judicial, y al otro, simplemente, poder ejecutivo del Estado. ${ }^{21}$

Puede verse que, en la configuración de Montesquieu, el Poder Judicial no tiene el perfil claro que ha logrado ahora. Entonces se trataba de un «poder ejecutivo del Estado» y tenía por finalidad resolver los problemas que ahora llamaríamos «penales» y «civiles». Hay que notar, también, que no existe una clara diferenciación entre la sanción in iudicando y la ejecución material de dicha sanción. Tampoco Montesquieu analiza los detalles de la vinculación de estos dos conceptos con la iurisdictio: el Poder Judicial no es tratado con claridad en esta obra.

LA REFORMA DEL PODER JUDICIAL DEBETENER

UNA DIMENSIÓN POLÍTICA DE LA QUENO SE HABLA 
Y luego, Montesquieu añade lo siguiente:

El poder judicial no debe darse a un Senado permanente, sino que lo deben ejercer personas del pueblo, nombradas en ciertas épocas del año de la manera prescrita por la ley, para formar un tribunal que solo dure el tiempo que la necesidad lo requiera.

De esta manera, el poder de juzgar, tan terrible para los hombres, se hace invisible y nulo, al no estar ligado a determinado estado o profesión. Como los jueces no están permanentemente a la vista, se teme a la magistratura, pero no a los magistrados.

Es preciso incluso que, en las acusaciones graves, el reo, conjuntamente con la ley, pueda elegir sus jueces, o al menos que pueda recusar tantos que, los que queden, puedan considerarse como de su elección. ${ }^{22}$

En este texto, su tratamiento del tema se centra en el aspecto in iudicando. No adopta ni discute el concepto de iurisdictio que venía desde Roma y que formaba parte de la tradición conceptual del tema de la administración de justicia. En realidad, este segundo párrafo de Del espíritu de las leyes es aun más restringido que el anterior, porque, en el primero, la atribución era perseguir el delito y solucionar los problemas privados de las personas, en tanto que este último trata, en estricto sentido, de juzgar y resolver. No hay una concepción del Poder Judicial dentro de la organización total del Estado.

$\mathrm{Al}$ ser esta la concepción de Montesquieu, y habiendo sido él una pieza clave en el desarrollo del sistema de separación de poderes en la historia reciente, es imaginable que se privara al Poder Judicial de la dimensión política de la iurisdictio romana. Si a esto sumamos la pretensión exitosa de los revolucionarios franceses en el sentido de que los jueces conservadores fueran la «boca de la ley» y que no aplicaran con sus raciocinios las leyes anteriores a la revolución, tenemos una explicación histórica más o menos cabal de por qué el Poder Judicial ha llegado hasta nosotros como es ahora.

\section{VII.CÓMO PODER DISEÑAR LAS FUNCIONES DE UN PODER JUDICIAL CON SUS DIMENSIONES POLÍTICA Y TÉCNICO-JURÍDICA}

Tal vez, antes de elaborar las líneas generales de propuesta sobre la combinación de lo político y lo técnico-jurídico dentro del Poder Judicial, sea importante decir por qué creemos que el tema debe ser abordado, en lugar de insistir una vez más solo en la dimensión técnico-jurídica.

Nuestra preocupación es política y consiste en que, fueran democráticos o tiránicos, tolerantes o intolerantes, ingeniosos o torpes, los poderes 
ejecutivos y legislativos que, a lo largo de la historia, han pretendido una reforma del Poder Judicial, no la han logrado. Y la razón por la que ello ha ocurrido es que un ente institucional de las dimensiones del Poder Judicial o se reforma a sí mismo o no lo reforma nadie.

Las instituciones son sistemas que tienen partes y principios de funcionamiento. Es una ley conocida que tienden a reproducirse y a permanecer con sus costumbres y tradiciones a menos que una voluntad política interna los transforme. Tal vez el gran fracaso de las reformas judiciales en el Perú se deba a que se quiso transformar las cosas desde fuera, con leyes o interventores que araron en el mar y no lograron establecer nuevos surcos.

En los últimos años, dos presidentes de la Corte Suprema han mostrado un decidido impulso por la transformación del Poder Judicial: los doctores Hugo Sivina y Francisco Távara. Sin embargo, ha sido bastante evidente que su proyecto no fue secundado entusiastamente ni por la Corte Suprema como un todo, ni por los jueces. Se habla mucho de reforma judicial pero, al tener que pasar a los hechos, la reforma muchas veces choca con la resistencia pasiva de quienes van a soportarla en su trabajo cotidiano.

La falta de voluntad de transformación interna del Poder Judicial se nota en muchos aspectos. Resalta, en la época de las comunicaciones universales, la forma arcaica de organizar el trabajo de procesamiento de los expedientes y el lenguaje de las sentencias. Hoy son mucho más inteligibles las resoluciones de los tribunales administrativos y las sentencias del Tribunal Constitucional que la redacción sin puntos aparte de los considerandos judiciales, técnica que, por lo demás, solo usan los jueces y se aprende en el ejercicio mismo de la judicatura — porque los estudiantes de Derecho jamás escriben sus textos de esa forma-. Es más: la forma en que el proceso judicial mismo es llevada no depende solo del código procesal respectivo. Es evidente que en la aplicación cotidiana de la labor jurisdiccional contemporánea existe una serie de costumbres y tradiciones que solo están en el Derecho porque el aparato judicial las conserva.

Para reintroducir la política en el Poder Judicial, tenemos que pensarlo más o menos íntegramente de nuevo. Hay que despercudirse de prejuicios y de herencias de la Revolución francesa y de Montesquieu, entre otros. Solo así se pueden rediseñar verdaderamente las cosas.

Consideramos que lo primero que debiera hacerse es repensar las funciones políticas y administrativas del Poder Judicial y separarlas de las estrictamente jurisdiccionales en el sentido actual de la palabra, es decir, de juzgar y sentenciar. Para ello, tomaremos como base la desagregación de funciones que la Ley Orgánica del Poder Judicial hace para la Sala Plena y el Consejo de Gobierno del Poder Judicial.

LA REFORMA DEL pODER JUDICIAL DEBE TENER UNA DIMENSIÓN POLÍTICA DE LA QUENO SE HABLA 
Para este efecto, las funciones políticas y administrativas, no jurisdiccionales en el sentido contemporáneo de la palabra, que ejercería el órgano de decisión política del Poder Judicial ${ }^{23}$ serían, a nuestro criterio, las siguientes: ${ }^{24}$

- Iniciativa legislativa conforme a la Constitución (artículo 80 inciso 1).

- Interposición de la Acción de Inconstitucionalidad (artículo 80 inciso 2).

- Aprobar cada tres años la política general y el Plan de Desarrollo del Poder Judicial (artículo 80 inciso 7).

- Aprobar el proyecto de presupuesto del Poder Judicial y sustentarlo ante el Congreso (artículo 80 inciso 8 y artículo 82 inciso 2).

- Aprobar el Reglamento General del Poder Judicial y los demás que se requiera (artículo 80 inciso 10 y artículo 82 inciso 35).

- Aprobar los reglamentos para la organización y la correcta realización de los procesos electorales del Poder Judicial (artículo 82 inciso 33).

- Crear y suprimir Distritos Judiciales, Salas y Juzgados cuando así lo requiera la más rápida y eficaz administración de justicia (artículo 80 inciso 18 y artículo 82 inciso 28).

- Reubicar Salas de Cortes Superiores y Juzgados a nivel nacional, así como aprobar la demarcación de los Distritos Judiciales y la modificación de sus ámbitos de competencia territorial para poder excepcionalmente incorporar Salas de Cortes Superiores Especializadas y Juzgados Especializados o Mixtos con competencia supraprovincial (artículo 82 inciso 29).

- Disponer que la Sala Interna de la Corte Suprema, en forma excepcional, distribuya las causas entre las Salas Especializadas, fijando sus competencias, a fin de descongestionar la carga judicial; además, conformar Salas Transitorias por un término no mayor de tres (03) meses, en casos estrictamente necesarios (artículos 80 inciso 12 y 82 inciso 20).

- Promover, en coordinación con la Academia de Altos Estudios en Administración de Justicia, la especialización, el perfeccionamiento y la actualización jurídica de los magistrados de toda la República a nivel de todas sus instancias (artículo 82 inciso 23).

23 Como veremos después, este órgano sería para nosotros el Consejo de Gobierno del Poder Judicial y, en una opción alternativa que es para nosotros la opción B, podría ser la Sala Plena de la Corte Suprema.

24 Al final de cada párrafo, consignamos el dispositivo de la Ley Orgánica del Poder Judicial en que tal función se halla. 
- Aprobar los reconocimientos y distinciones que se otorguen a los magistrados por servicios excepcionales prestados en favor de la Administración de Justicia. Dichos reconocimientos se otorgan durante la ceremonia del Día del Juez (artículos 80 inciso 11 y 82 inciso 37).

- Resolver, conforme a su reglamento, los asuntos relativos a traslados de magistrados, funcionarios y demás servidores del Poder Judicial (artículo 82 inciso 12).

- Adoptar acuerdos y demás medidas para que las dependencias del Poder Judicial funcionen con celeridad y eficiencia y para que los magistrados y demás servidores del Poder Judicial se desempeñen con la mejor conducta funcional (artículo 82 inciso 31).

- Velar por el respeto de las atribuciones y garantías del Poder Judicial en los aspectos no jurisdiccionales (artículo 82 inciso 4).

- Desarrollar los sistemas de informática que faciliten una eficiente función de gestión, el eficaz control de la conducta funcional y del trabajo jurisdiccional de todos los miembros del Poder Judicial y la organización estadística judicial, conforme a las propuestas que le formule la Gerencia General (artículo 82 inciso 25).

- Acordar el horario de despacho judicial de la Corte Suprema (artículo 82 inciso 6).

- Aprobar el Cuadro de Términos de la Distancia, así como revisar periódicamente el valor de los costos, multas y depósitos correspondientes y otros que se establezcan en el futuro (artículo 82 inciso 7).

- Resolver en última instancia las reclamaciones contra los acuerdos y resoluciones de la autoridad política de los distritos judiciales (artículo 82 inciso 5).

- Resolver en última instancia las medidas de apercibimiento, multa y suspensión impuestos por la Oficina de Control Interno contra los magistrados y, en su caso, todas las dictadas contra los demás funcionarios y servidores del Poder Judicial (artículo 82 inciso 11).

- Fijar las cuantías y sus reajustes para determinar las competencias jerárquicas (artículo 82 inciso 13).

- Designar comisiones de asesoramiento, investigación y estudio (artículo 82 inciso 14).

- Designar al Jefe de la Oficina de Inspectoría General del Poder Judicial (artículo 82 inciso 34). 
- Designar, cada tres años, al Vocal Jefe de la Oficina de Control de la Magistratura (artículo 80 inciso 3).

- Designar al Gerente General del Poder Judicial, al Director del Centro de Investigaciones Judiciales y a los demás funcionarios que señalen la ley y los reglamentos (artículo 82 inciso 15).

- Nombrar y designar a los empleados de la Corte Suprema, de la Dirección de Administración del Poder Judicial, de los Órganos de Apoyo, de la Oficina de Control Interno del Poder Judicial y de la Corte Suprema, en este último caso, a su propuesta (artículo 82 inciso 16).

- Celebrar toda clase de convenios de cooperación e intercambio dentro de la constitución y las leyes, con entidades nacionales o extranjeras, para asegurar el financiamiento de sus programas y el cumplimiento de sus fines; en tal sentido, fijar la metodología pertinente y ejercer el control de la aplicación de los fondos respectivos, y dar cuenta a la Sala Plena de la Corte Suprema (artículo 82 inciso 26).

- Asegurar el pago íntegro de las remuneraciones de los magistrados y demás servidores del Poder Judicial, según lo establecido en esta ley (artículo 82 inciso 27).

- Otorgar en concesión los servicios conexos y complementarios a la Administración de Justicia, tales como notificaciones y depósitos, conforme a las normas del Decreto Legislativo 758, y actuar para el efecto como organismo concedente (artículo 82 inciso 36).

- Adoptar todas las otras medidas que fueran necesarias para asegurar la eficaz y oportuna administración de justicia, los derechos de los magistrados y demás funcionarios servidores del Poder Judicial y de los justiciables (artículo 80 inciso 17).

Las funciones que corresponderían a la Corte Suprema como máximo órgano jurisdiccional del Estado serían:

- Conocer en casación las causas que ella elija resolver según convenga a la política jurisprudencial del Estado.

- Elegir, entre sus miembros, a los representantes de la Corte Suprema ante el Consejo Nacional de la Magistratura (artículo 80 inciso 4).

- Elegir al representante de la Corte Suprema ante el Jurado Nacional de Elecciones (artículo 80 inciso 5).

- Supervisar en forma permanente y obligatoria, mediante vocales visitadores elegidos de su seno, la labor que cumplen conforme a 
ley los órganos jurisdiccionales de todo el Poder Judicial (artículo 80 inciso 13). Pueden pedir, de los organismos jurisdiccionales, los informes que consideren pertinentes para supervisar mejor la administración de justicia del Estado.

- Denunciar directamente a los miembros del Poder Judicial y del Ministerio Público que incumplan sus precedentes jurisdiccionales.

Por su parte, las funciones del Presidente del Poder Judicial serían las siguientes:

- Presidir el Poder Judicial y el órgano de gobierno, establecer su agenda y ejecutar sus decisiones.

- Formular y ejecutar la política general y el Plan de Desarrollo del Poder Judicial (artículo 82 inciso 1).

- Ejercer la titularidad del Pliego del Presupuesto del Poder Judicial, cuya responsabilidad es compartida solidariamente por todos sus integrantes (artículo 82 inciso 3).

Asegurar la distribución oportuna del diario oficial El Peruano a todos los magistrados de la república (artículo 82 inciso 18).

- Garantizar la conservación y el buen recaudo de los bienes incautados cuya libre disposición esté supeditada a la resolución de los juicios penales (artículo 82 inciso 19).

- Asegurar la progresiva habilitación y adecuación de locales judiciales a escala nacional en los cuales funcionen los órganos jurisdiccionales con su respectivo personal auxiliar (artículo 82 inciso 21).

- Velar por la conservación y el mantenimiento de los locales judiciales, sus servicios públicos y demás condiciones que garanticen el buen servicio judicial (artículo 82 inciso 22).

- Asumir la defensa pública de los magistrados que hayan sido ultrajados en su honorabilidad por declaraciones hechas en los medios de comunicación social (artículo 82 inciso 24).

- Ordenar la publicación de la jurisprudencia (artículo 82 inciso 30).

De esta manera, consideramos que el órgano de gobierno tomaría las decisiones políticas necesarias para el desarrollo del Poder Judicial, la Corte Suprema sería un órgano esencialmente jurisdiccional y el Presidente del Poder Judicial sería quien conduzca la política general y quien la ejecute.

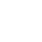




\section{ELESQUEMA INSTITUCIONALPARA EL GOBIERNO DEL PODER JUDICIAL}

Las ideas precedentes exigirían tres niveles de decisión dentro del Poder Judicial. En el orden en que los trataremos, serán la Corte Suprema, un Consejo de Gobierno y un Presidente del Poder Judicial.

\section{La Corte Suprema de la República}

En nuestro concepto, una decisión central para la reforma de todo el sistema es reconfigurar la Corte Suprema. Ya hemos dicho que consideramos indispensable reformar la concepción que de ella tiene la Constitución. Para tal propósito, proponemos este párrafo:

La Corte Suprema es el órgano del Poder Judicial que dirige la actividad jurisdiccional del Estado mediante precedentes jurisdiccionales que vinculan la decisión de todos quienes ejercen la jurisdicción en el Perú, salvo el Tribunal Constitucional. La Corte Suprema podrá juzgar sobre todo proceso resuelto jurisdiccionalmente por las cortes superiores, por el Consejo Supremo de Justicia Militar y por las autoridades de las comunidades campesinas y nativas dentro de su territorio, los que le serán comunicados bajo responsabilidad. Elegirá los procesos a resolver para determinar precedentes jurisprudenciales vinculantes, teniendo su resolución efecto también entre las partes. Juzga en primera y segunda instancia los casos que determinan la Constitución y las leyes (en esencia, el juzgamiento de altos magistrados de la República). En su labor jurisdiccional la Corte Suprema es independiente de toda autoridad extraña, incluidos el Consejo de Gobierno y el Presidente del Poder Judicial. Los vocales de la Corte Suprema tienen inmunidad por los votos que emitan. Son responsables por no respetar sus fallos precedentes pero, la Corte Suprema, podrá apartarse de ellos fundadamente y para futuro, cuando así lo considere y motive.

Desde luego, esta no será la definición constitucional: es una definición institucional que pretende establecer los rasgos esenciales que en adelante tendrá este órgano del Estado. Así, la Corte Suprema ya no será ni instancia ni corte de casación. Estas no son sus finalidades. Su existencia se justificará porque sienta precedentes jurisdiccionales que dirigen la actividad jurisdiccional de la república.

Tendrá que organizarse de manera que pueda asumir esta responsabilidad, distinta de la que ha tenido a lo largo de su historia. Deberá lograr capacidad para elegir los casos a resolver, que deberán ser gravitantes dentro de la política jurisprudencial, y tendrá que dotarse del personal técnico idóneo que le permita cumplir esa tarea.

La Corte Suprema deberá supervisar a todos los organismos de administración de justicia y velar, específicamente, porque su jurisprudencia sea obedecida y cumplida. Si no fuera así, hay que dotarla de un procedimiento expeditivo de denuncia penal por delito contra la administración de 
justicia. Deberá organizarse para hacerlo eficientemente y en respeto de los derechos constitucionales de los denunciados.

La Corte Suprema tendría un presidente elegido entre sus pares, que conduciría la labor jurisdiccional y de supervisión. Los vocales de la Corte Suprema deberían ser elegidos según requisitos que garanticen no solo que podrán dictar una línea de política jurisprudencial vinculante sino, además, que aseguren que pueden realizar la actividad de supervisión de la administración de justicia. El vocal de la Corte Suprema no deberá ser solamente un buen jurista sino, también, una persona con capacidades de conducción institucional en materia jurisdiccional.

Esta Corte Suprema no debería tener las dimensiones de la actual. Tal vez siete o nueve miembros, de los cuales uno la presidiría, serían un número adecuado para las nuevas funciones. Los vocales de la Corte Suprema, en esta propuesta, no deberán tener legitimación democrática en su elección. Por tanto, pueden ser designados de la manera en que hoy está previsto en la Constitución. Con el tipo de trabajo que realizarían, no necesitarían estar divididos en salas.

\section{El Consejo de Gobierno}

El Consejo de Gobierno debería ser un organismo pluripersonal en el que participaran el Presidente de la Corte Suprema y un grupo reducido de ciudadanos elegidos en forma indirecta para formar parte de él.

La elección debería ser llevada a cabo entre postulantes que cumplan determinados requisitos establecidos en la ley, que supongan que conocen la labor jurisdiccional y que tienen experiencia de conducción institucional. Ni solo lo uno ni solo lo otro. No deberían ser solo abogados, pues es una función política, no técnico-jurídica. Desde luego, decimos esto teniendo en cuenta lo que acabamos de considerar como requisito: que deben saber de la labor jurisdiccional. ${ }^{25}$

Tendría que ser un Consejo de Gobierno formado por ciudadanos a dedicación exclusiva, con funciones de gobierno según se ha visto antes y con funciones ejecutivas bajo la conducción del Presidente del Poder Judicial, de manera que pudieran llevar a cabo las decisiones políticas que se tome. El número no debiera ser grande sino pequeño: tal vez cinco, de manera que con el Presidente de la Corte Suprema y el Presidente del Poder Judicial fueran un total de siete personas.

LA REFORMA DEL PODER JUDICIAL DEBETENER UNA DIMENSIÓN POLÍTICA DE LA QUE NO SE HABLA 
Creemos que la elección de estos miembros debería ser hecha por un Colegio Electoral ${ }^{26}$ conformado al efecto. Es verdad que esta fórmula tiene un costo, pero la democracia es de alta civilización y tiene costos económicos. La situación actual del Poder Judicial tiene otros costos económicos y políticos aun mayores.

Una alternativa es la de encargar el nombramiento al Congreso si es unicameral, o al Senado, si finalmente se llegan a establecer dos cámaras, con una mayoría calificada alta, como, por ejemplo, la que tiene el nombramiento de los miembros del Tribunal Constitucional. Pero para nosotros es la opción B, la de menor calidad, porque, al fin y al cabo, el nombramiento por el Congreso es eso, un nombramiento, y no tiene el peso político de una elección popular aunque ella sea indirecta.

\section{El Presidente del Poder Judicial}

El Presidente del Poder Judicial debería ser el gobernante de esta rama de la organización del Estado y tendría que ser elegido como tal de la misma forma que los miembros del Consejo de Gobierno. También aquí cabe la opción B que, como en el caso anterior, tiene menor calidad democrática. Este Presidente del Poder Judicial deberá tener derecho a antejuicio político como requisito previo a su enjuiciamiento, lo que se incorporaría, para tal efecto, a los artículos 99 y 100 de la Constitución.

Será el conductor del Consejo de Gobierno del Poder Judicial y la instancia ejecutiva de todo el aparato. Su mandato debería ser de la extensión del que corresponde al Presidente de la República.

\section{Una opción B también en la parte institucional del Poder Judicial}

Consideramos posible una opción $\mathrm{B}$ de organización de la cúpula del Poder Judicial para efectos de otorgarle institucionalidad política y jurisdiccional.

En este caso, estimamos, debería haber una Corte Suprema de un número como el que ya hemos dicho - siete a nueve vocales_, quienes deberían ser elegidos como hemos propuesto que lo sean los miembros del Consejo de Gobierno en los párrafos previos: o un colegio electoral de democracia indirecta o el Congreso de la República con votación calificada. Deberían cumplir requisitos específicos de conocer la materia jurídica — por lo que deberían ser todos abogados—y tener condiciones

26 Aquí tratamos solo acerca del Poder Judicial, pero es preciso decir que hay otros funcionarios de hoy día que debieran ser tambiénelegidos paratenerun mandato democráticoenelEstado. Estamos pensandoen elDefensordelPueblo,losmismosmiembrosdelTribunalConstitucional,elFiscaldelaNación,elContralor General de la República y varios de los superintendentes. Ello les permitiría ejercitar mejor sus funciones y perfeccionaría el sistema de pesos y contrapesos en la separación de poderes. De esta manera, un colegioelectoral de altas autoridades podría tener trabajo adicional al que aquítratamos. Perotodoestoes materia distinta de la que hoy nos ocupa, aunqueel problema de legitimación democrática sea comúna los gobernantes del Poder Judicial y a otros magistrados de la república. 
de liderazgo y administración. No vale, nuevamente, tener una de estas capacidades sin tener la otra.

La Corte Suprema tendría una organización para la administración de justicia propiamente dicha y otra para las decisiones de gobierno. La organización para la administración de justicia podría incluir salas y plenos jurisdiccionales. La organización para el gobierno debería significar que la Corte vota como sala plena y que sus miembros tienen también responsabilidades administrativas y de supervisión de la administración de justicia. Esta es una doble forma de organización que no presenta problemas de concepto porque, de hecho, la corte ya la tiene en la actualidad, aunque intermediada por el Consejo de Gobierno que se prevé genéricamente en el artículo 143 de la Constitución y que es desarrollado en la Ley Orgánica del Poder Judicial.

Debemos decir que, a nuestro criterio, perfeccionar el diseño es más fácil en la perspectiva que nosotros proponemos que en la que tiene actualmente la Constitución porque, dentro de esta última, la Corte Suprema trabaja presionada por un volumen de carga jurisdiccional imposible de cumplir. En la propuesta nuestra, su dedicación a la tarea jurisdiccional será más profunda y menos extensa, y le permitirá desarrollar más la labor de gobierno y supervisión.

Desde luego, de las listas de atribuciones que hicimos antes, la Corte debería en este caso tomar las que corresponden al órgano de gobierno y las que le son propias como órgano jurisdiccional.

En cualquier caso, también en esta opción B la Corte Suprema debería ser considerada como un órgano de conducción política en dos aspectos - jurisdiccional y de gobierno judicial — y no debería ser considerada como un órgano de resolución de procesos, salvo naturalmente los procesos excepcionales que se tramitan ante ella en primera y segunda instancia por rara excepción -y que, como dijimos antes, son fundamentalmente los juicios penales de altos magistrados de la república-.

\section{A MANERA DE REFLEXIÓN FINAL}

Como puede verse, esta propuesta no constituye una politización del aparato de administración de justicia. El argumento según el cual «los magistrados no deben teñirse de política y deben tener un nombramiento de origen técnico» solo toma en cuenta la necesidad de que los jueces administren justicia con calidad jurídica. En eso tiene razón, pero no mira en absoluto el tremendo problema de gobierno que hay en la actualidad —y que hubo en el pasado— para con la administración de justicia. Tampoco repara en que los jueces se consideran resolutivos de procesos y no conductores de la pacificación de la sociedad a través de la función jurisdiccional. 
Por consiguiente, el problema de legitimación democrática del gobierno del Poder Judicial debería ser abordado. La democracia tiene muchas fórmulas, y hacer campaña en volantes y mítines de plaza para obtener el voto popular no es la única forma. Los sistemas de democracia indirecta existen desde hace miles de años y tienen por finalidad atemperar lo que hoy llamamos «populismo» pero, al mismo tiempo, buscan garantizar legitimidad para el uso del poder. Es la combinación que hay que lograr.

Como se ha visto a lo largo de estas páginas, creemos que el esfuerzo esencial para devolver la dimensión política a la reforma judicial consiste en tres asuntos:

- El primero es reformular la finalidad de la Corte Suprema en su dimensión jurisdiccional. Debería dejar de ser instancia o corte de casación para convertirse en conductora de la política jurisdiccional del Estado. En esto desarrolla capacidades técnico-jurídicas y la única función política es la de orientar con sus decisiones vinculantes la administración de justicia de todo el Estado. Lo que acabamos de decir no es innovación alguna. Es lo que hacen muchas cortes supremas y otros altos tribunales en el mundo. La particularidad de nuestra propuesta, en este punto, es que nosotros creemos que la historia republicana peruana demuestra que la Corte Suprema, tal como está concebida en nuestro país, tiende a ser resolutiva de procesos y no conductora de la labor jurisdiccional. Por consiguiente, hay que cambiar su finalidad, sus funciones, su modo de operación y el criterio con que se nombra a sus vocales.

- El segundo es dar dirección política a las funciones que no son jurisdiccionales, sino de gobierno y administración. Quienes conduzcan al Poder Judicial en estos ámbitos deberían tener legitimidad democrática en su elección. Con ella pueden o no reformar al Poder Judicial pero, con el sistema de gobierno actual, hay prácticamente una garantía de que no habrá una reforma profunda sino, más bien, una reproducción de las características esenciales y tradicionales que tiene. Por lo demás, la dimensión política está plenamente legitimada en la historia de los dos grandes sistemas jurídicos occidentales contemporáneos, uno de los cuales, el romano-germánico, es el que llega a nosotros.

- Para todo ello, hay que hacer un esfuerzo por diferenciar las funciones estrictamente jurisdiccionales de las de gobierno y administración, y crear una institucionalidad que permita independizar el ejercicio de cada una de ellas. Es una tarea pendiente para la que hemos hecho una propuesta inicial, sometida a discusión. 